\title{
2-D analytical winding losses model of micro-inductor
}

Li, Yangkun ; Mao, Xingkui; Zhu, Jungao ; Dong, Jiqing; Zhang, Zhe

Published in:

Proceedings of 45th Annual Conference of the IEEE Industrial Electronics Society

Link to article, DOI:

10.1109/IECON.2019.8926792

Publication date:

2020

Document Version

Peer reviewed version

Link back to DTU Orbit

Citation (APA):

Li, Y., Mao, X., Zhu, J., Dong, J., \& Zhang, Z. (2020). 2-D analytical winding losses model of micro-inductor. In Proceedings of 45th Annual Conference of the IEEE Industrial Electronics Society IEEE. https://doi.org/10.1109/IECON.2019.8926792

\section{General rights}

Copyright and moral rights for the publications made accessible in the public portal are retained by the authors and/or other copyright owners and it is a condition of accessing publications that users recognise and abide by the legal requirements associated with these rights.

- Users may download and print one copy of any publication from the public portal for the purpose of private study or research.

- You may not further distribute the material or use it for any profit-making activity or commercial gain

- You may freely distribute the URL identifying the publication in the public portal

If you believe that this document breaches copyright please contact us providing details, and we will remove access to the work immediately and investigate your claim. 


\section{2-D analytical winding losses model of micro-inductor}

\author{
Yangkun Li \\ College of Electrical Engineering and
Automation
Fuzhou University
Fuzhou, China
n170120043@fzu.edu.cn
}

Jiqing Dong

College of Electrical Engineering and Automation

Fuzhou University

Fuzhou, China

dongjiqing@fzu.edu.cn

\author{
Xingkui Mao \\ College of Electrical Engineering and \\ Automation \\ Fuzhou University \\ Fuzhou, China \\ mxk782@fzu.edu.cn \\ Zhe Zhang \\ Department of Electrical Engineering \\ Technical University of Denmark \\ Kgs. Lyngby, Denmark \\ zz@elektro.dtu.dk
}

\author{
Jungao Zhu \\ Shenzhen Lifud Technology Co., Ltd \\ Shenzhen, China \\ zhujungaojob@126.com
}

\begin{abstract}
Since the magnetic field distribution in winding window of thin film micro-inductor with closed magnetic core has obvious 2-D characteristics, the accuracy of 1-D analytical model for its winding AC losses is poor. The magnetic field of the micro-inductor is analyzed deeply to show that its distribution along the winding edge does not change with frequency. According to the analysis result, the magnetic field strength around the winding edge is calculated with the Ampere's law. And the 2-D magnetic field is decomposed into an $x$ component and $y$ component in rectangular coordinates. Then based on the superposition and uniqueness law of magnetic field, a 2-D analytical winding losses model of thin film micro-inductor is proposed. Finally, the finite element analysis (FEA) simulation verified the loss model to have high accuracy under wide exciting current frequency and the loss model can be used easily.
\end{abstract}

Keywords-micro-inductor, thin film, winding losses, magnetic field, 2-D analytical winding losses model

\section{INTRODUCTION}

The rapid development of network information technology promotes continuous increase of processor frequency, and also puts forward new requirements on its power supply capacity, power density and dynamic response, resulting in the popular point power supply solutions to be difficult to meet the requirements gradually. In order to improve the power supply performance of the processor and reduce influences imposed by stray parameters of the power supply components and leading wire, researchers proposed and tried to integrate the processor with its power supply to realize the chip-based power supply, i.e. power supply on chip.

In order to realize power supply on chip, its operation frequency needs to be increased to megahertz or even hundreds of megahertz to reduce the power supply to size of the processor. Due to development of semiconductor power components, packaging technology and high-density capacitor integration technology, the biggest bottleneck limitation on the power supply on chip is integration of energy storage power inductors. The micro-inductor operating with megahertz frequency features small size, light weight and high power density. Considering volume limitation of the power supply on chip, and requirements on core material, manufacturing process when the inductor operates with megahertz frequency, the thin film micro-inductor is considered to be key breakthrough technology to realize power supply on chip [1]-[6].

The thin film micro-inductor operates with low voltage and high current. Due to its very small winding cross-sectional area, the current density of the winding may reach tens or even hundreds of $\mathrm{A} / \mathrm{mm}^{2}$ to make the winding losses density very large. In addition, because operation frequency of the microinductor is usually in megahertz or even hundreds of megahertz, eddy current induced by alternate magnetic field makes current distribution uneven, which lead to extremely high current density in parts of the winding, resulting in great $\mathrm{AC}$ winding losses. Because of the integration of the micro-inductor and the processor, the temperature rise caused by the winding losses will seriously affect the processor operation. Therefore, the winding losses is a key issue to be considered in the design of micro-inductor, and good design depends on the loss accurate prediction .

Now winding losses of high frequency power magnetic components is mainly modeled with 1-D analytical model [7][13]. When external magnetic field is parallel to the winding surface, i.e. the magnetic field in the winding window is with 1-D distribution, the 1-D analytical model has high enough accuracy to be used conveniently in engineering. While the magnetic field in micro-inductor features strongly with 2-D distribution. Therefore, the previous 1-D analytical winding losses model is not applicable to calculating the micro-inductor winding losses [14],[15]. Although 2-D finite element analysis can be used to simulate and analyze 2-D magnetic field to get high accurate result, FEA meshing at high frequency needs to be enough, which makes simulation time-consuming [16],[17]. Moreover, numerical simulation is not convenient for analysis and optimal design. The semi-empirical method combining with analytical model and numerical simulation is used to analyze winding losses under 2-D effect, which improves the 
calculation accuracy [18]-[20]. However, these methods need a lot of simulation results as the basic data, which is not suitable for engineering design. Reference [21] proposed a 2-D analytical model, but its process is relatively complex and not convenient for engineering.

This paper is structured as follows. After this Introduction, Section II analyze magnetic field distribution in the winding window of thin film micro-inductor with closed magnetic core. Section III describes to calculate the magnetic field strength along the winding edge and its decomposition. Section IV proposes a 2-D analytical winding losses model. Section V verifies the winding losses model with commercial FEA simulator Maxwell. Finally the conclusion is given in Section VI.

\section{MAGNEetic FIELD Distribution Of ThIN FILM MICRO-INDUCTOR}

Anisotropy of magnetic crystal in the micro-inductor film core not only effectively reduce high frequency core losses, but also improve the inductor saturation performance. Among the thin film micro-inductors, the racetrack structure is preferred to be typical because it adopts closed magnetic film core structure which can effectively improve the inductor power density, and the anisotropy of magnetic crystal can greatly reduce the inductor loss, and it is to be convenient manufacturing. The racetrack structure diagram is shown in Fig. 1, and blue dot line A is central location of the winding.

In order to analyze the magnetic field distribution of thin film micro-inductor, the magnetic field strength is simulated with commercial FEA simulator Maxwell. The simulation magnetic field strength along the central dot line A of the winding in Fig.1 (b) is shown in Fig. 2. Since magnetic core of thin film micro-inductor is closed, and the magnetic motive force (MMF) is uniformly in the magnetic film core, the magnetic field along the line $\mathrm{A}$ is zigzag distribution and the magnetic field strength component in $\mathrm{y}$ axis varies with $\mathrm{x}$ location in the insulating layer between two adjacent windings. That is to say, the magnetic field strength has not only the $y$ component, but also its $\mathrm{x}$ component cannot be ignored, and the distribution of magnetic field has obvious 2-D characteristics. Using the traditional 1-D analytical model to calculate the losses of thin film micro-inductor winding with closed magnetic core will have a large deviation and is no longer applicable. Therefore, this paper proposes a 2-D analytical model for predicting the winding AC losses of thin film micro-inductor.

\section{Caculation Of The Magnetic Field StRength ARound EDGE OF THE WINDING}

In order to construct the 2-D analytical winding losses model of the micro-inductor, the magnetic field strength around edge of the winding should be calculated. Aiming to calculate the magnetic field strength, the following assumptions are made:

- The magnetic field strength y component $H_{\mathrm{y}}$ only changes with $\mathrm{x}$, while the $\mathrm{x}$ component $H_{\mathrm{x}}$ only changes with $\mathrm{y}$ (coordinate axis definition is shown in Fig. 3).

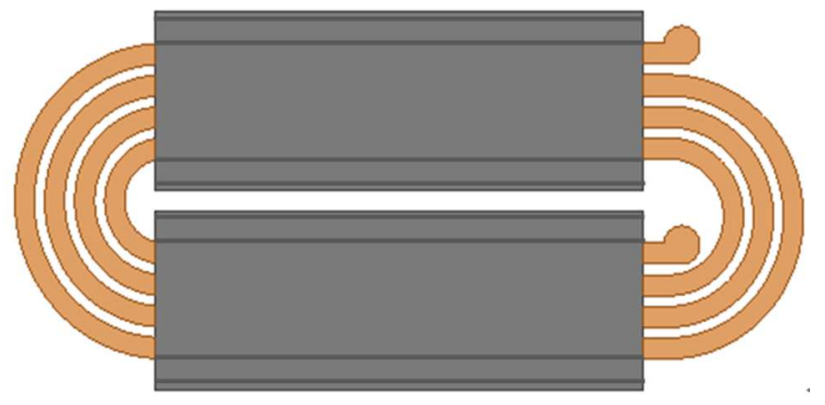

(a) Top view

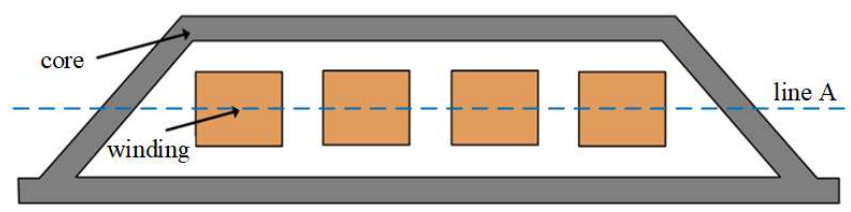

(b) Cross sectional view

Fig. 1. The diagram of racetrack thin film micro-inductor

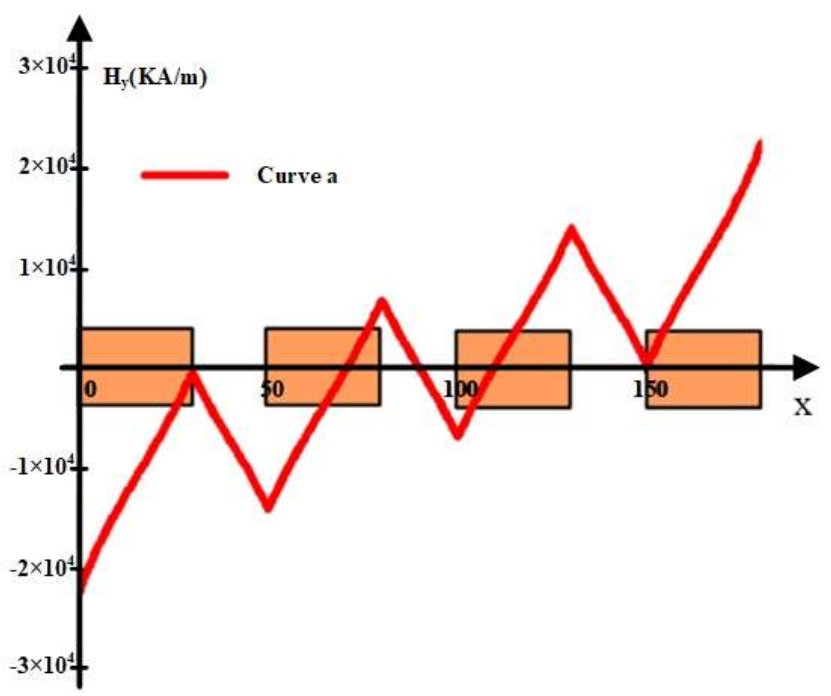

Fig. 2. Distribution of magnetic field strength along the line A

- The magnetic core material is linear, and the magnetic field strength in the film core is evenly.

According to the Ampere's law, the magnetic field strength in the film core can be expressed as

$$
H_{\text {core }}=\frac{N I}{l_{\mathrm{q}}}
$$

Where, $I$ is amplitude of the winding current, $N$ is number of winding turns, and $l_{\mathrm{q}}$ is the magnetic circuit length along the inner surface of the magnetic core.

$$
l_{\mathrm{q}}=2\left[N w_{\mathrm{cu}}+(N-1) w_{\mathrm{gap}}+\left(t_{\mathrm{cu}}+2 h_{\mathrm{su}}\right) \frac{(\cos a+1)}{\sin a}\right]
$$

Where, conductor width $w_{\mathrm{cu}}$, conductor thickness $t_{\mathrm{cu}}$, adjacent winding distance $w_{\text {gap }}$, insulation layer thickness $h_{\mathrm{su}}$ and core leg angle are $\alpha$ shown in Fig. 3 . 


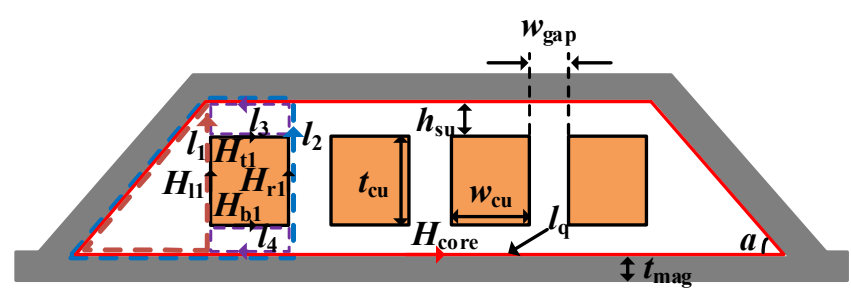

Fig. 3. Cross sectional view of the racetrack thin film micro-inductor

According to the Ampere's law, the magnetic field strength $H_{l 1}$ of loop $l_{1}$ (red dot line) which along the left edge of the first turn winding is

$$
H_{l 1}=\frac{-(\cos a+1)}{\sin a} H_{\text {core }}
$$

Then, Along loop $l_{2}$ with blue dot line, the magnetic field strength $H_{\mathrm{r} 1}$ of the right edge of the first turn winding:

$$
H_{\mathrm{r} 1}=\frac{-\left[\left(t_{\mathrm{cu}}+2 h_{\mathrm{su}}\right) \frac{(\cos a+1)}{\sin a}+2 w_{\mathrm{cu}}\right] H_{\mathrm{core}}+I}{t_{\mathrm{cu}}+2 h_{\mathrm{su}}}
$$

Calculating the magnetic field strength $H_{\mathrm{r} 1}$ of the top edge of the first turn winding based on loop $l_{3}$ as follows:

$$
H_{\mathrm{t} 1}=\frac{-H_{\mathrm{r} 1} \cdot h_{\mathrm{su}}-H_{\mathrm{core}} \cdot w_{\mathrm{cu}}+H_{l 1} \cdot h_{\mathrm{su}}}{w_{\mathrm{cu}}}
$$

The magnetic field strength $H_{\mathrm{b} 1}$ along loop $l_{4}$ of the bottom edge of the first turn winding are likewise calculated as follows:

$$
H_{\mathrm{b} 1}=\frac{H_{\mathrm{r} 1} h_{\mathrm{su}}+H_{\mathrm{core}} w_{\mathrm{cu}}-H_{l 1} h_{\mathrm{su}}}{w_{\mathrm{cu}}}
$$

So, the magnetic field strength of the left, right, top and bottom edges of any winding are as follows:

$$
\begin{array}{r}
H_{l, \mathrm{i}}=\frac{-\left[\left(t_{\mathrm{cu}}+2 h_{\mathrm{su}}\right)(\cos a+1) / \sin a\right] H_{\mathrm{core}}}{t_{\mathrm{cu}}+2 h_{\mathrm{su}}}+ \\
H_{\mathrm{r}, \mathrm{i}}=\frac{-\left[\left(t_{\mathrm{cu}}+2 h_{\mathrm{su}}\right)(\cos a+1) / \sin a\right] H_{\mathrm{core}}+}{\left.\left.t_{\mathrm{cu}}+2 h_{\mathrm{su}}+w_{\mathrm{gap}}\right)\right] H_{\mathrm{core}}+(i-1) I} \\
\\
\frac{\left.-2\left[i w_{\mathrm{cu}}+(i-1) w_{\mathrm{gap}}\right)\right] H_{\mathrm{core}}+i I}{t_{\mathrm{cu}}+2 h_{\mathrm{su}}} \\
H_{\mathrm{t}, \mathrm{i}}=\frac{-h_{\mathrm{su}} H_{\mathrm{r}, \mathrm{i}}-w_{\mathrm{cu}} H_{\mathrm{core}}+h_{\mathrm{su}} H_{l, \mathrm{i}}}{w_{\mathrm{cu}}} \\
H_{\mathrm{b}, \mathrm{i}}=\frac{h_{\mathrm{su}} H_{\mathrm{r}, \mathrm{i}}+w_{\mathrm{cu}} H_{\mathrm{core}}-h_{\mathrm{su}} H_{l, \mathrm{i}}}{w_{\mathrm{cu}}}
\end{array}
$$

Where $i=1,2 \ldots N$. It should be pointed out that in Fig. 3, $H_{\mathrm{t}, \mathrm{i}}=-H_{\mathrm{b}, \mathrm{i}}$ means that the magnetic field strength value of the top and bottom edges of the winding is the same but the direction is opposite.

In order to check the above calculation of the magnetic field strength, a racetrack thin film micro-inductor example is constructed. The inductor parameters are: $N=4, w_{\mathrm{cu}}=30 \mathrm{um}$, $t_{\mathrm{cu}}=20 \mathrm{um}, w_{\mathrm{gap}}=20 \mathrm{um}$, film core thickness $t_{\mathrm{mag}}=6 \mathrm{um}, h_{\mathrm{su}}=5 \mathrm{um}$, $\alpha=45^{\circ}$, and exciting current amplitude $I=1 \mathrm{~A}$. The magnetic field strength of the left and right edges of the each winding was calculated with the above magnetic field calculation method, and compared with the magnetic field strength simulated by FEA simulator Maxwell to be shown in Fig. 4.

In Fig. 4, the magnetic field strength comparing between the calculation and the FEA simulation is under different frequency of $100 \mathrm{kHz}, 20 \mathrm{MHz}$ and $100 \mathrm{MHz}$. . It can be seen that although the distribution of magnetic field strength in the winding changes with operation or exciting current frequency, but the frequency has only slight influence on the magnetic field strength of the space between the adjacent winding, and there is good consistence between the calculation and the simulation, i.e it verifies the calculation has merit of high accuracy in the winding edge.

\section{2-D ANALYTICAL Winding LosSES Model}

\section{A. Winding losses decomposition at high frequency}

Because magnetic field distribution in the winding window of racetrack thin film micro-inductor shown in Fig. 3 features of two dimension obviously, the traditional 1-D analytical model is no longer suitable for the winding losses calculation of the inductor. In order to accurately calculate the winding AC losses, a 2-D analytical model is proposed. According to the characteristics of magnetic field distribution, the 2-D magnetic field is decomposed into y axis component field $H_{\mathrm{N}}$ being vertical to the winding conductor surface, and $\mathrm{x}$ axis component field $H_{\mathrm{S}}$ being parallel to the winding conductor surface as shown in Fig. 5. And the 2-D eddy current field decomposition is to be noted with " $\times$ " and "•" which represents the current density vector pointing vertically into the paper and out of the paper respectively in Fig. 5. The current density of $J_{\mathrm{P}}$ and $J_{\mathrm{S}}$ induced by $H_{\mathrm{N}}$ and $H_{\mathrm{S}}$ component field respectively can be obtained by the Ampere's law and Maxwell's eddy current equations. Then based on the superposition principle and the uniqueness law of the electromagnetic field, the total current density induced by the 2-D magnetic field can be obtained by addition of the two component $J_{\mathrm{P}}$ and $J_{\mathrm{S}}$, then the analytical winding losses is modeled.

Where, the $H_{\mathrm{N}}$ component field is induced by the excitation current of the winding itself and the adjacent winding, and this component field will induce winding losses including skin effect losses and proximity effect loss. The $H_{\mathrm{S}}$ component field is only induced by the excitation current of the winding, and there is no magnetic field induced by the current of its adjacent winding because of only one layer winding in 


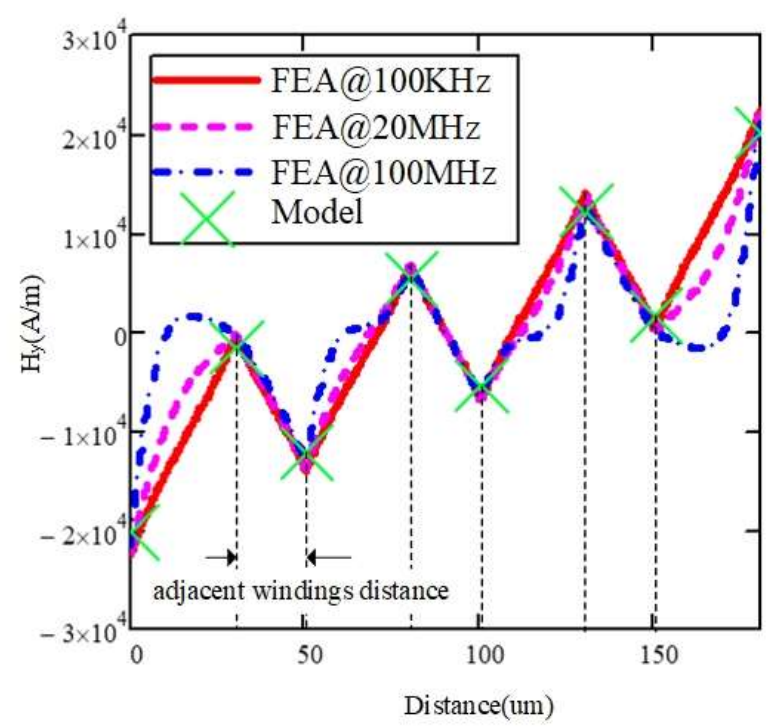

Fig. 4. Comparison of calculation and simulation magnetic field strength along the line $\mathrm{A}$

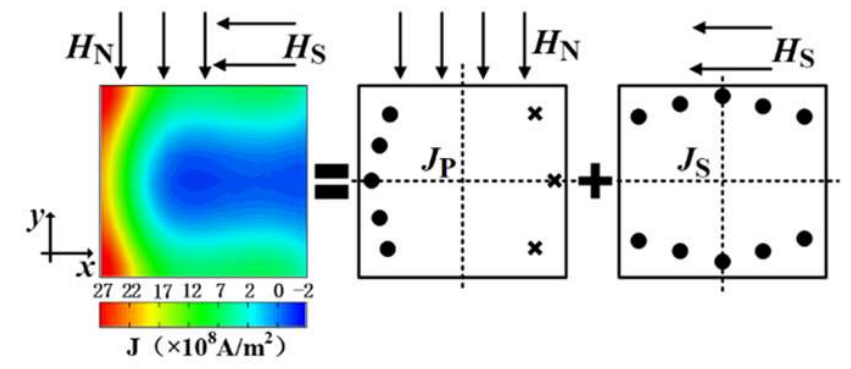

Fig. 5. Decomposition of 2-D eddy current field

the thin film inductor. So, the $H_{\mathrm{S}}$ component field only induce skin effect loss, and no proximity effect loss.

\section{B. y component eddy current effect loss}

In order to solve the current density induced by $H_{\mathrm{N}}$ component field, the winding magnetic field boundary conditions corresponding to y component is shown in Fig. 6 (a) based on the above assumptions in Section III. The winding internal magnetic field strength $H_{\mathrm{y}}(x)$ can be described by second order Helmholtz equation as

$$
\frac{d^{2} H_{\mathrm{y}}(x)}{d x^{2}}=j \omega \mu \sigma H_{\mathrm{y}}(x)=k^{2} H_{\mathrm{y}}(x)
$$

Its general solution is

$$
H_{\mathrm{y}}(x)=H_{1} e^{k \cdot x}+H_{2} e^{-k \cdot x}
$$

According to the magnetic field boundary conditions of the winding conductor,

$$
\begin{gathered}
H_{\mathrm{y}}(0)=H_{1}+H_{2} \\
H_{\mathrm{y}}\left(w_{\mathrm{cu}}\right)=H_{1} e^{k \cdot w_{\mathrm{cu}}}+H_{2} e^{-k \cdot w_{\mathrm{cu}}}
\end{gathered}
$$

$H_{1}$ and $H_{2}$ can be solved by (13) and (14)

$$
\left\{\begin{array}{l}
H_{1}=\frac{H_{\mathrm{y}}\left(w_{\mathrm{cu}}\right)-H_{\mathrm{y}}(0) \cdot e^{-k \cdot w_{\mathrm{cu}}}}{\sinh \left(k \cdot w_{\mathrm{cu}}\right) / 2} \\
H_{2}=\frac{H_{\mathrm{y}}(0) \cdot e^{k \cdot w_{\mathrm{cu}}}-H_{\mathrm{y}}\left(w_{\mathrm{cu}}\right)}{\sinh \left(k \cdot w_{\mathrm{cu}}\right) / 2}
\end{array}\right.
$$

Where $k=\sqrt{j \omega \sigma \mu}, \sigma$ is conductivity of the winding conductor, $\mu$ is the relative permeability of air, and $\omega$ is exciting current angular frequency.

By substituting equation (15) into equation (12), the magnetic field in the winding can be obtained as follows:

$$
H_{\mathrm{y}}(x)=\frac{H_{\mathrm{y}}(0) \sinh \left[k\left(w_{\mathrm{cu}}-x\right)\right]+H_{\mathrm{y}}\left(w_{\mathrm{cu}}\right) \sinh (k x)}{\sinh \left(k w_{\mathrm{cu}}\right)}
$$

So, the current density of the winding can be got as

$$
\begin{gathered}
J_{\mathrm{z}}(x)=\frac{d H_{\mathrm{y}}(x)}{d x}=-k\left\{\frac{H_{\mathrm{y}}(0) \cosh \left[k\left(w_{\mathrm{cu}}-x\right)\right]}{\sinh \left(k w_{\mathrm{cu}}\right)}-\right. \\
\left.\frac{H_{\mathrm{y}}\left(w_{\mathrm{cu}}\right) \cosh (k x)}{\sinh \left(k w_{\mathrm{cu}}\right)}\right\}
\end{gathered}
$$

Where, $J_{\mathrm{z}}(x)$ is current density induced by $H_{\mathrm{y}}(\mathrm{x})$, and it only changes with $\mathrm{x}$.

\section{C. $x$ component skin effect loss}

Since the magnetic field of the top and bottom edges of the winding is same in value and the direction is opposite, it can be considered that the magnetic field strength $H_{\mathrm{S}}$ is only induced by the winding current itself, i.e there is only one layer winding. So, the winding losses in $\mathrm{x}$ component is only induced by the skin effect. The magnetic field boundary conditions of $H_{\mathrm{S}}$ component field is shown in Fig. 6 (b). The current density $J_{\mathrm{z}}(\mathrm{y})$ induced by $H_{\mathrm{S}}$ can be solved by the following Helmholtz equation and the boundary conditions as follows:

$$
\begin{aligned}
J_{\mathrm{Z}}(y)=-\frac{d H_{\mathrm{x}}(y)}{d y}= & k\left\{\frac{H_{\mathrm{x}}(0) \cosh \left[k\left(t_{\mathrm{cu}}-y\right)\right]}{\sinh \left(k t_{\mathrm{cu}}\right)}-\right. \\
& \left.\frac{H_{\mathrm{x}}\left(t_{\mathrm{cu}}\right) \cosh (k y)}{\sinh \left(k t_{\mathrm{cu}}\right)}\right\}
\end{aligned}
$$

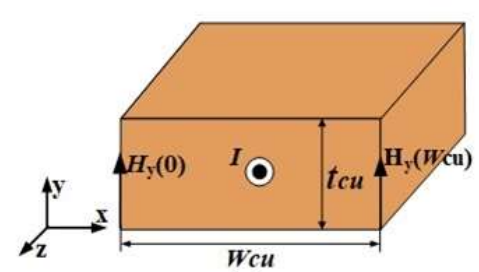

(a)

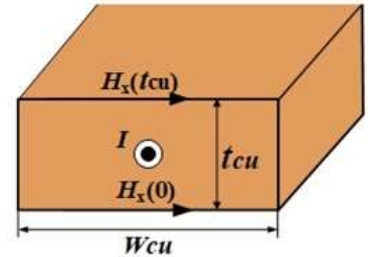

(b)
Fig. 6. Conductor magnetic field boundary condition 
Then the AC winding losses per unit winding length in $\mathrm{x}$ component is

$$
\begin{aligned}
P= & \frac{w_{\mathrm{cu}}}{2 \sigma} \int_{0}^{t_{\mathrm{cu}}}\left|J_{\mathrm{Z}}(y)\right|^{2} d y=P_{\mathrm{S}}+P_{\mathrm{P}}= \\
& \frac{w_{\mathrm{cu}}}{4 \sigma \delta}\left|H_{\mathrm{x}}\left(t_{\mathrm{cu}}\right)-H_{\mathrm{x}}(0)\right|^{2} \frac{\sinh v+\sin v}{\cosh v-\cos v}+ \\
& \frac{w_{\mathrm{cu}}}{4 \sigma \delta}\left|H_{\mathrm{x}}\left(t_{\mathrm{cu}}\right)+H_{\mathrm{x}}(0)\right|^{2} \frac{\sinh v-\sin v}{\cosh v+\cos v}
\end{aligned}
$$

Where, $P_{\mathrm{S}}$ is the losses caused by skin effect, $P_{\mathrm{P}}$ is the losses caused by proximity effect, is relative thickness and the expression is $v=t_{\mathrm{cu}} / \delta, \delta$ is skin depth and its expression is $\delta=1 / \sqrt{\pi f \sigma \mu}$.

$H_{\mathrm{x}}\left(t_{\mathrm{cu}}\right)+H_{\mathrm{x}}(0)=0$ can be obtained from equation (9) and equation (10). Therefore, there is no losses caused by proximity effect in x component, only skin effect losses exists. This is consistent with the above analysis.

\section{Total AC losses of the winding}

Based to the superposition principle and the uniqueness law of electromagnetic field, the current density vectors corresponding to $H_{\mathrm{S}}$ component field and $H_{\mathrm{N}}$ component field are added to form the total current density. Therefore, according to equation (17) and equation (18), the total ac winding losses per unit length of a single turn winding can be calculated as

$$
P_{\mathrm{ac}}=\frac{1}{2 \sigma} \iint\left(\left|J_{\mathrm{z}}(y)+J_{\mathrm{z}}(x)\right|\right)^{2} d x d y
$$

The total AC losses per unit length of $N$ turns winding of the thin film micro-inductor is

$$
P_{\text {ac_total }}=\sum_{i=1}^{N} P_{\mathrm{ac}}(i)
$$

Where, $i$ is the number of the winding.

\section{THE FEA SimUlation VERIFICATION}

In order to verify the 2-D analytical winding losses model, several inductors (L1, L2, L3) were simulated. The magnetic film material of the simulation inductor is selected as $\mathrm{Ni}_{45} \mathrm{Fe}_{55}$. Its relative permeability is 280 , and resistivity is $45 \mathrm{u} \Omega * \mathrm{~cm}$. The structural parameters of the inductor is shown in Table I. The aspect ratio of winding cross section $A R$ defines with $t_{\mathrm{Cu}} / w_{\mathrm{Cu}}$.

The AC winding losses at different frequency are calculated with the proposed 2-D analytical winding losses model, and the calculation losses is compared with the simulation by finite element analysis simulation software Maxwell. The calculation and FEA simulation winding losses with $1 \mathrm{~A}$ exciting current at different frequency are shown in Fig. 7. From Fig. 7, it can be seen that the calculation winding losses with the proposed 2-D analytical model is in good agreement with the FEA simulation in frequency range from $100 \mathrm{kHz}$ to $100 \mathrm{MHz}$. Fig. 8 shows the winding losses deviation curve between the 2-D analytical
TABLE I. Structural Parameters OF The Thin Film MICRO-INDUCTORS(UNIT: $u m$ )

\begin{tabular}{|c|c|c|c|}
\hline Inductor & $t_{\mathrm{cu}}$ & $w_{\mathrm{cu}}$ & $\mathrm{AR}$ \\
\hline L1 & 20 & 20 & 1 \\
\hline L2 & 20 & 60 & $1 / 3$ \\
\hline L3 & 20 & 100 & $1 / 5$ \\
\hline \multicolumn{4}{|c|}{$N=8$ truns, $w_{\text {gap }}=20, h_{\mathrm{su}}=5, t_{\mathrm{mag}}=6, \alpha=45^{\circ}$} \\
\hline
\end{tabular}

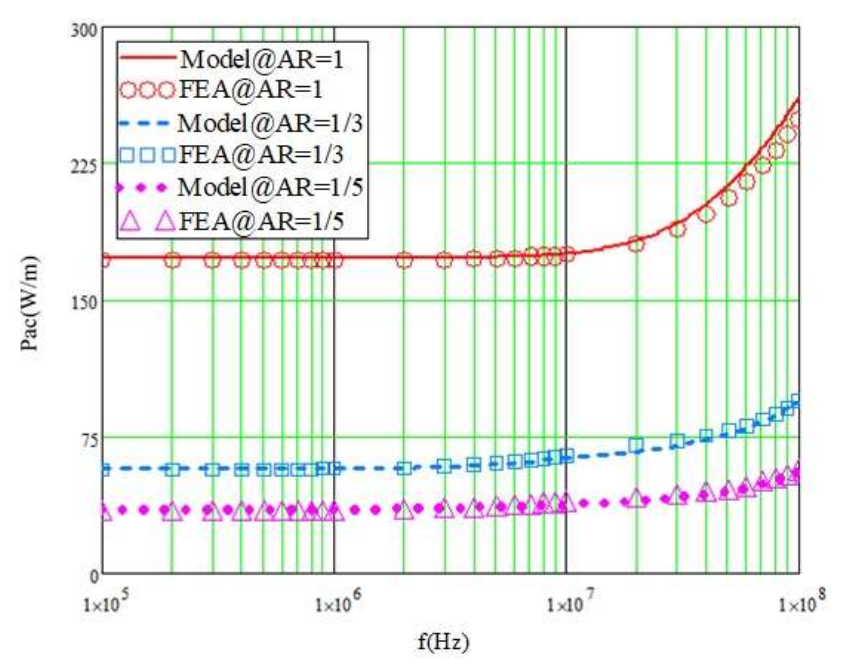

Fig. 7. The calculation and FEA simulation AC winding losses

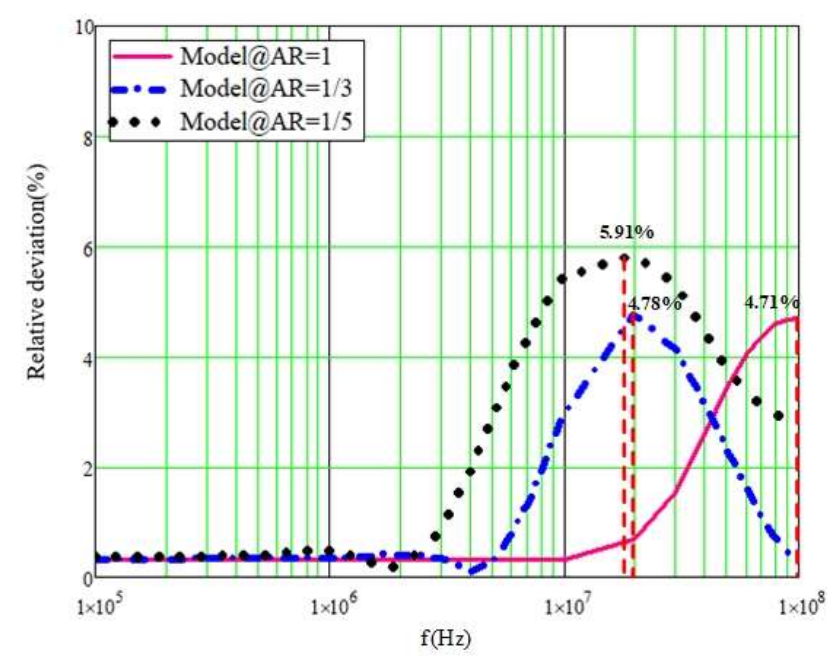

Fig. 8. The model deviation analysis

model and FEA simulation. It can be seen that the deviation is almost zero in the frequency range from $100 \mathrm{kHz}$ to $3 \mathrm{MHz}$. And from about $3 \mathrm{MHz}$ to $100 \mathrm{MHz}$, the largest deviation is $5.91 \%$, and it has enough accuracy for engineering applications. When $A R$ is equal to 1 (L1), the maximum deviation is $4.71 \%$. $A R$ is equal to $1 / 3$ (L2), the maximum deviation is $4.78 \%$. And when $A R$ is equal to $1 / 5$ (L3), the maximum deviation is $5.91 \%$.

It can be seen that when $A R$ is no more than 1 , the $2-\mathrm{D}$ analytical model has high accuracy in the frequency range of $100 \mathrm{kHz}$ to $100 \mathrm{MHz}$. Due to the limitations of manufacturing conditions, the thin film micro-inductor windings often adopt structures with $A R$ less than 1, so the proposed 2-D analytical 
model can accurately calculate the AC losses of thin film micro-inductor windings. And the systematic model is convenient to calculate the winding losses with any turns $(N$ turns) in engineering.

\section{CONCLUSION}

In this paper, the magnetic field distribution in the winding window is analyzed and the analytical winding losses model of the racetrack thin film micro-inductor with magnetic core closed structure is researched. And the following conclusions are drawn:

- The magnetic field distribution of thin film microinductor has obvious 2-D characteristics. 1-D analytical model is no longer suitable for calculating the AC winding losses.

- The magnetic field strength in the space between the adjacent winding or of left and right edges of the winding do not change with different frequency, even if the magnetic field in internal space of the winding changes dramatically. The magnetic field of the top and bottom edges of the winding is equal in value and opposite in direction. For thin film micro-inductor with closed core, the magnetic field in the winding can be decomposed into component field in y dimension and component field in $\mathrm{x}$ dimension. The losses corresponding to the $H_{\mathrm{S}}$ field is only induced by skin effect loss, and there is no proximity effect loss.

- The proposed 2-D analytical model can calculate the winding losses of thin film micro-inductor with high accuracy, and the deviation with the FEA simulation is less than $6 \%$ in the wide frequency range of $100 \mathrm{kHz}$ to $100 \mathrm{MHz}$. This conclusion can be extended to model the winding losses with the similar 2-D magnetic field distribution.

\section{ACKNOWLEDGMENT}

The authors gratefully acknowledge the financial support by Natural Science Foundation of Fujian Province (2017J01689, 2018J01756).

\section{REFERENCES}

[1] S. C. O. Mathuna, T. O'Donnell, Ningning Wang and K. Rinne, "Magnetics on silicon: an enabling technology for power supply on chip," IEEE Trans. Power Electron., vol. 20, no. 3, pp. 585-592, May 2005.

[2] R. Meere, T. O'Donnell, H. J. Bergveld, N. Wang and S. C. O'Mathuna, "Analysis of microinductor performance in a $20-100 \mathrm{MHz}$ DC/DC converter," IEEE Trans. Power Electron., vol. 24, no. 9, pp. 2212-2218, Sept. 2009.

[3] D. S. Gardner, G. Schrom, F. Paillet, B. Jamieson, T. Karnik and S. Borkar, "Review of on-chip inductor structures with magnetic films," IEEE Trans. Magn., vol. 45, no. 10, pp. 4760-4766, Oct. 2009.

[4] N. Wang et al., "Integrated magnetics on silicon for power supply in package (PSiP) and power supply on chip (PwrSoC)," 3rd Electronics System Integration Technology Conference ESTC, Berlin, 2010, pp. 1-6.
[5] D. Yao and C. R. Sullivan, "Optimization of V-groove inductors using multilayer Co-Zr-O thin films for $10 \mathrm{MHz}$ to $100 \mathrm{MHz}$ dc-dc converters," 2010 IEEE 12th Workshop on Control and Modeling for Power Electronics (COMPEL), Boulder, CO, 2010, pp. 1-5.

[6] C. Ó. Mathúna, N. Wang, S. Kulkarni and S. Roy, "Review of Integrated Magnetics for Power Supply on Chip (PwrSoC)," IEEE Trans. Power Electron., vol. 27, no. 11, pp. 4799-4816, Nov. 2012

[7] P. L. Dowell, "Effects of eddy currents in transformer windings," in Proceedings of the Institution of Electrical Engineers, vol. 113, no. 8, pp. 1387-1394, August 1966.

[8] J. -. Vandelac and P. D. Ziogas, "A novel approach for minimizing highfrequency transformer copper losses," IEEE Trans. Power Electron., vol. 3, no. 3, pp. 266-277, July 1988.

[9] J. A. Ferreira, "Improved analytical modeling of conductive losses in magnetic components," IEEE Trans. Power Electron., vol. 9, no. 1, pp. 127-131, Jan. 1994.

[10] J. M. Boggetto, Y. Lembeye, J. P. Ferrieux and J. P. Keradec, "Copper losses in power integrated inductors on silicon," Conference Record of the 2002 IEEE Industry Applications Conference. 37th IAS Annual Meeting (Cat. No.02CH37344), Pittsburgh, PA, USA, 2002, pp. 977-983 vol.2.

[11] Xi Nan and C. R. Sullivan, "An improved calculation of proximityeffect loss in high-frequency windings of round conductors," IEEE 34th Annual Conference on Power Electronics Specialist, 2003. PESC '03., Acapulco, Mexico, 2003, pp. 853-860 vol.2.

[12] R. P. Wojda and M. K. Kazimierczuk, "Winding resistance and power loss of inductors with litz and solid-round wires," IEEE Trans. Ind. Appl., vol. 54, no. 4, pp. 3548-3557, July-Aug. 2018.

[13] D. J. Whitman and M. K. Kazimierczuk, "An analytical correction to Dowell's equation for inductor and transformer winding losses using cylindrical coordinates," IEEE Trans. Power Electron., in press.

[14] R. Severns, "Additional losses in high frequency magnetics due to non ideal field distributions," [Proceedings] APEC '92 Seventh Annual Applied Power Electronics Conference and Exposition, Boston, MA, USA, 1992, pp. 333-338.

[15] F. Robert, P. Mathys, B. Velaerts and J. -. Schauwers, "Twodimensional analysis of the edge effect field and losses in highfrequency transformer foils," IEEE Trans. Magn., vol. 41, no. 8, pp. 2377-2383, Aug. 2005.

[16] Z. Zhang, K. D. T. Ngo and J. L. Nilles, "Design of inductors with significant AC flux," IEEE Trans. Power Electron., vol. 32, no. 1, pp. 529-539, Jan. 2017.

[17] B. Chen and L. Li, "Semi-Empirical model for precise analysis of copper losses in high-frequency transformers," IEEE Access, vol. 6, pp. 36553667, 2018.

[18] F. Robert, P. Mathys and J. -. Schauwers, "A closed-form formula for 2D ohmic losses calculation in SMPS transformer foils," IEEE Trans. Power Electron., vol. 16, no. 3, pp. 437-444, May 2001.

[19] I. Lope, C. Carretero, J. Acero, J. M. Burdío and R. Alonso, "Practical issues when calculating $\mathrm{AC}$ losses for magnetic devices in PCB implementations," 2012 Twenty-Seventh Annual IEEE Applied Power Electronics Conference and Exposition (APEC), Orlando, FL, 2012, pp. 1017-1022.

[20] D. V. Harburg, Jizheng Qiu and C. R. Sullivan, "An improved AC loss model for the optimization of planar-coil inductors," 2012 IEEE 13th Workshop on Control and Modeling for Power Electronics (COMPEL), Kyoto, 2012, pp. 1-7.

[21] N. Wang, T. O’Donnell and C. O’Mathuna, "An improved calculation of copper losses in integrated power inductors on silicon," IEEE Trans. Power Electron., vol. 28, no. 8, pp. 3641-3647, Aug. 2013. 